\title{
Stratospheric water vapour in the vicinity of the Arctic polar vortex
}

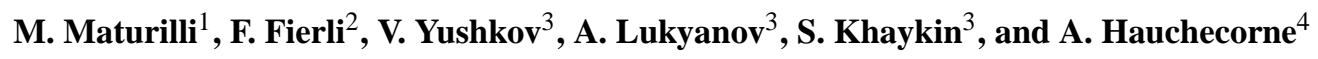 \\ ${ }^{1}$ Alfred Wegener Institute for Polar and Marine Research, Potsdam, Germany \\ ${ }^{2}$ Institute for Atmospheric Sciences and Climate, CNR, Italy \\ ${ }^{3}$ Central Aerological Observatory, Moscow, Russia \\ ${ }^{4}$ Service D'Aéronomie du CNRS, Verrières-le-Buisson, France
}

Received: 28 July 2005 - Revised: 13 April 2006 - Accepted: 19 April 2006 - Published: 3 July 2006

\begin{abstract}
The stratospheric water vapour mixing ratio inside, outside, and at the edge of the polar vortex has been accurately measured by the FLASH-B Lyman-Alpha hygrometer during the LAUTLOS campaign in Sodankylä, Finland, in January and February 2004. The retrieved $\mathrm{H}_{2} \mathrm{O}$ profiles reveal a detailed view on the Arctic lower stratospheric water vapour distribution, and provide a valuable dataset for the validation of model and satellite data. Analysing the measurements with the semi-lagrangian advection model MIMOSA, water vapour profiles typical for the polar vortex' interior and exterior have been identified, and laminae in the observed profiles have been correlated to filamentary structures in the potential vorticity field. Applying the validated MIMOSA transport scheme to specific humidity fields from operational ECMWF analyses, large discrepancies from the observed profiles arise. Although MIMOSA is able to reproduce weak water vapour filaments and improves the shape of the profiles compared to operational ECMWF analyses, both models reveal a dry bias of about $1 \mathrm{ppmv}$ in the lower stratosphere above $400 \mathrm{~K}$, accounting for a relative difference from the measurements in the order of $20 \%$. The large dry bias in the analysis representation of stratospheric water vapour in the Arctic implies the need for future regular measurements of water vapour in the polar stratosphere to allow the validation and improvement of climate models.
\end{abstract}

Keywords. Atmospheric composition and structure (Middle atmosphere-composition and chemistry)- Meteorology and atmospheric dynamics (Middle atmosphere dynamics; Polar meteorology)

\section{Introduction}

Water vapour is a chemically, physically, and radiatively active trace gas, and its distribution in the stratosphere determines significant climatic implications. The observed in-

Correspondence to: $\mathrm{M}$. Maturilli

(mmaturilli@awi-potsdam.de) crease in stratospheric water vapour (Oltmans and Hofmann, 1995; Evans et al., 1998; Oltmans et al., 2000, Rosenlof et al., 2001) is believed to contribute to the recent downward trend in stratospheric temperatures (Forster and Shine, 1999; Smith et al., 2001; Oinas et al., 2001), and its changing concentration modifies the stratospheric radiative balance. Furthermore, stratospheric humidity has an influence on ozone depletion by affecting both the formation temperature of polar stratospheric clouds (PSCs) and the polar vortex temperatures themselves (Kirk-Davidoff et al., 1999).

In the absence of condensation, the stratospheric water vapour abundance is controlled by photochemistry and dynamics. In the upper stratosphere, methane oxidation accounts for the primary water vapour source within the stratosphere (Abbas et al., 1996; Michelsen et al., 2000), generally leading to an increase of $\mathrm{H}_{2} \mathrm{O}$ from the lowermost stratosphere to the stratopause. In the tropics, vertical transport from the troposphere provides the other important source of stratospheric water vapour, limited by freeze drying at the cold tropical tropopause (Brewer, 1949).

The overall hemispheric water vapour distribution arises from the superimposed general circulation that accumulates trace gases by descent within the polar vortex. While in the midlatitudes rather constant values of about 4 to 5 ppmv $\mathrm{H}_{2} \mathrm{O}$ are found in the lower stratosphere (Ovarlez and Ovarlez, 1994; Schiller et al., 1996), the downward transport within the polar vortex yields higher water vapour mixing ratios from the source regions. Consequently, a horizontal gradient across the vortex edge arises in the lower stratosphere with higher mixing ratios inside than outside of the vortex as far as dehydration by sedimenting PSC particles can be excluded.

The water vapour mixing ratio inside and in the vicinity of the polar vortex has been accurately measured by several balloon-borne sensors during the LAUTLOS campaign in Sodankylä, Finland, in January and February 2004. The retrieved $\mathrm{H}_{2} \mathrm{O}$ profiles reveal a unique view on the lower stratospheric water vapour distribution in the Arctic, and present a valuable dataset for the validation of model and satellite data. The actual quantity of stratospheric water vapour in the

Published by Copernicus GmbH on behalf of the European Geosciences Union. 
Arctic is an important parameter not only for ozone chemistry, but also to infer the radiative budget and the resulting vertical motion inside the polar vortex.

In our study, we combine the stratospheric $\mathrm{H}_{2} \mathrm{O}$ profiles measured by the FLASH-B Lyman-Alpha hygrometer during the LAUTLOS campaign and the semi-lagrangian advection model MIMOSA (Hauchecorne et al., 2002). The model has been validated earlier and proven to be an excellent tool to analyse small scale dynamical structures at the edge of the polar vortex (Heese et al., 2001; Müller et al., 2003). To proceed from qualitative studies to the quantitative comparison of measurements and model analysis, we introduce operational stratospheric ECMWF specific humidity analyses to be compared with the measured $\mathrm{H}_{2} \mathrm{O}$ profiles. Taking advantage of the high resolution achieved with the MIMOSA advection scheme, we further analyse the Arctic water vapour distribution by applying MIMOSA three-dimensional field reconstructions to specific humidity fields.

\section{Balloon-borne measurements of stratospheric water vapour in the Arctic}

During the LAUTLOS campaign in Sodankylä $\left(26.65^{\circ} \mathrm{E}\right.$, $67.25^{\circ} \mathrm{N}$ ), Finland, in January/February 2004, different balloon-borne water vapour sensors were launched in combined payloads for intercomparison. The participating instruments suitable for the detection of water vapour in the stratosphere were the NOAA-CMDL frostpoint hygrometer (Vömel et al., 1995; Oltmans et al., 2000), the Colorado University cryogenic frostpoint hygrometer and the Fluorescent Advanced Stratospheric Hygrometer for Balloon (FLASHB) that has been developed at the Central Aerological Observatory in Russia (Yushkov et al., 1998; 2001). Due to the more consistent dataset during the campaign, we refer in our study to the measurements of the FLASH-B hygrometer, in the following noted as FLASH. The instrument applies the photofragment fluorescence method (Kley and Stone, 1978; Bertaux and Dellanoy, 1978) which is based on the photodissociation of $\mathrm{H}_{2} \mathrm{O}$ molecules when exposed to radiation with wavelengths $\lambda<121.6 \mathrm{~nm}$ (Lyman-Alpha hydrogen emission), here provided by a hydrogen discharge lamp. The generated electronically excited $\mathrm{OH}$ relaxes to the ground state by fluorescence in the $308-316 \mathrm{~nm}$ range, as well as by collision with air molecules. FLASH detects the $\mathrm{OH}$ fluorescence with a photomultiplier run in photon counting mode, and the intensity of the fluorescent light is directly proportional to the water vapour mixing ratio under stratospheric conditions with negligible oxygen absorption. As the instrument uses an open layout it is only suitable for nighttime measurements at solar zenith angles larger than $98^{\circ}$. FLASH-B is a light-weight $(\sim 1 \mathrm{~kg})$ and small size $(150 \mathrm{~mm} \times 200 \mathrm{~mm} \times 350 \mathrm{~mm})$ instrument with an estimated total uncertainty of less than $10 \%$ under stratospheric conditions. The FLASH measurements have been validated by the long-established NOAA-CMDL hygrometer, and the instrument has been approved to provide stratospheric water vapour data of similar quality (Vömel et al., $2005^{1}$ ). Good agreement of the FLASH measurements has also been found with ground-based microwave observations (Deuber et al., 2005).

During the campaign, 11 profiles of water vapour in the stratosphere have been detected by FLASH between 29 January and 25 February 2004. The stratospheric payloads were launched at 17:00 UTC, reaching the stratosphere at about 18 UTC. Due to contamination effects while ascending in the plume of the balloon, only descent data are taken into account. Overall, measurements have been taken inside, outside and at the edge of the polar vortex according to its location relative to the launch site. During the campaign period, the lower and mid-stratosphere showed a highly disturbed temperature and circulation pattern as a consequence of a major warming. At the end of January 2004, the vortex split into one centre over the west-siberian plain and a second centre over northern Europe. The cold pool was situated over Northern Siberia where the main vortex reinforced during February.

The correlation of the dynamical progression of the polar vortex and the stratospheric water vapour distribution is analysed by applying the semi-lagrangian advection model MIMOSA as described in the next sections. The LAUTLOS campaign yields the first dataset of high-resolution stratospheric water vapour profiles in the Arctic over a time period of about 1 month, and thus provides an excellent source for model validation.

\section{Behaviour of water vapour in the proximity of the po- lar vortex}

In the absence of condensation and freezing, water vapour is a valuable tracer for stratospheric transport processes since its photochemical lifetime in the lower stratosphere is in the order of years (Brasseur and Solomon, 1984). Along with the general circulation, stratospheric water vapour is descending inside the polar vortex, causing both a vertical gradient with higher mixing ratio in higher altitudes, and a horizontal gradient across the vortex edge. The vortex edge itself is usually not characterized by a simple first order discontinuity in potential vorticity, but tends to filamentation caused by the irreversible breaking of planetary waves (Appenzeller and Holton, 1997). These mesoscale filament structures and the according distribution of tracers in the proximity of the polar vortex are commonly simulated using either the reverse domain filling or the contour advection technique (Waugh et al., 1994; Newman et al., 1996). Also Lagrangian models have

\footnotetext{
${ }^{1}$ Vömel, H., Yushkov, V., Khaykin, S., Korshunov, L., Kyrö, E., and Kivi, R.: Intercomparisons of stratospheric water vapor sensors: FLASH-B and NOAA/CMDL frost point hygrometer, J. Geophys. Res., submitted, 2005.
} 

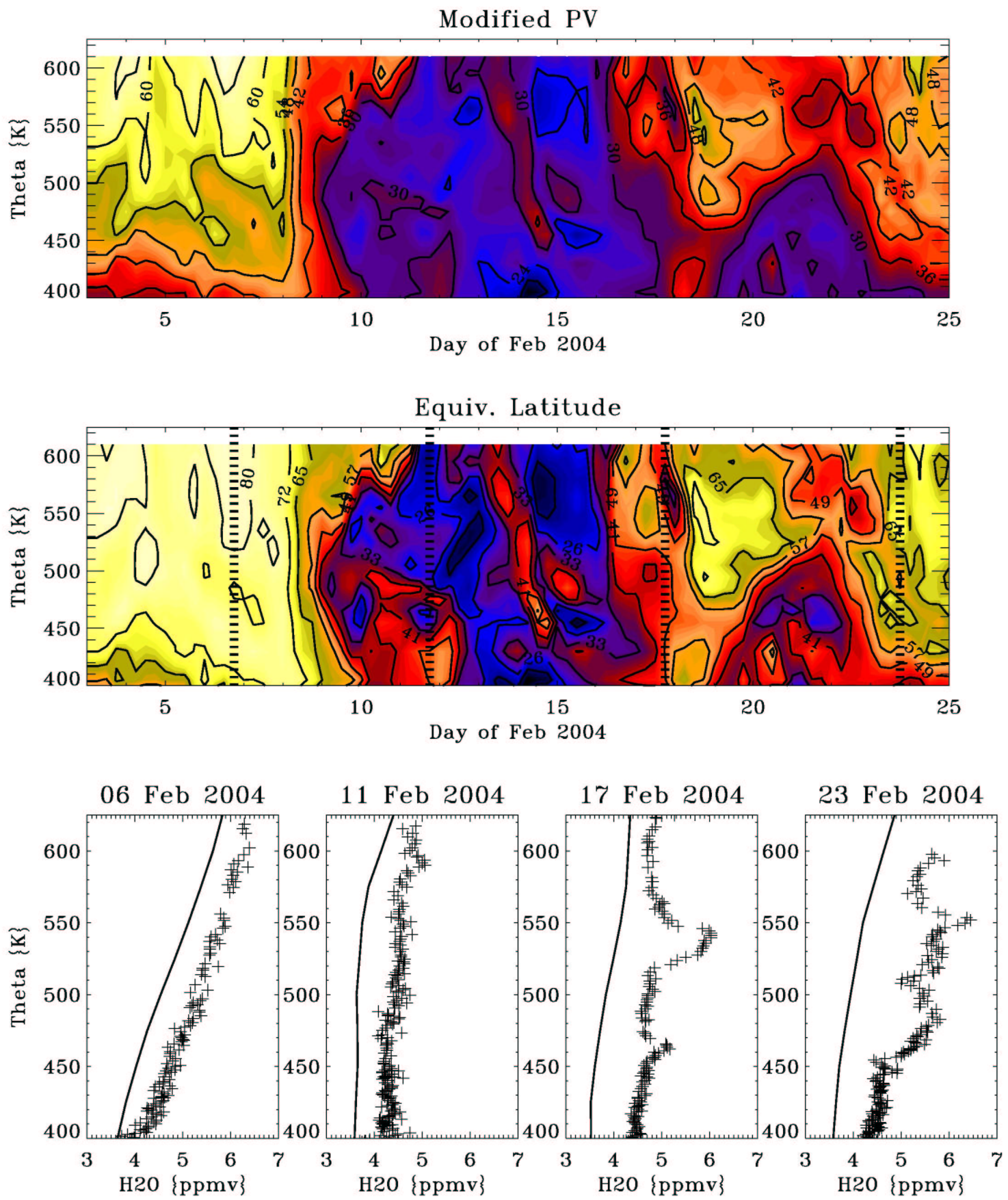

Fig. 1. Upper panel: MIMOSA modified PV (Lait, 1994) normalized at $475 \mathrm{~K}$, with contour lines every 6 PVU for the time period 01 to 25 February 2004 above Sodankylä. Centre panel: MIMOSA equivalent latitude (Nash et al., 1996) with contour lines every $8^{\circ}$ for the same period, with dotted lines indicating the date of the profiles shown below. Lower panel: Profiles of water vapour from ECWMF T106 analyses (black lines), and as measured by FLASH (black crosses) on 06, 11, 17, and 23 February 2004.

proven to reliably reproduce filamentary structures especially in the polar regions (e.g. McKenna et al., 2002). In our study, we apply the semi-lagrangian advection model MIMOSA (Hauchecorne et al., 2002) to the period of the LAUTLOS campaign. Based on the operational 6-hourly ECMWF wind and temperature data extracted on pressure levels with $1.125^{\circ} \times 1.125^{\circ}$ horizontal resolution, the MIMOSA transport scheme produces tracer fields with $0.3^{\circ}$ horizontal resolution on interpolated isentropic surfaces. To analyse the dynamical influence on the measured water vapour profiles, 


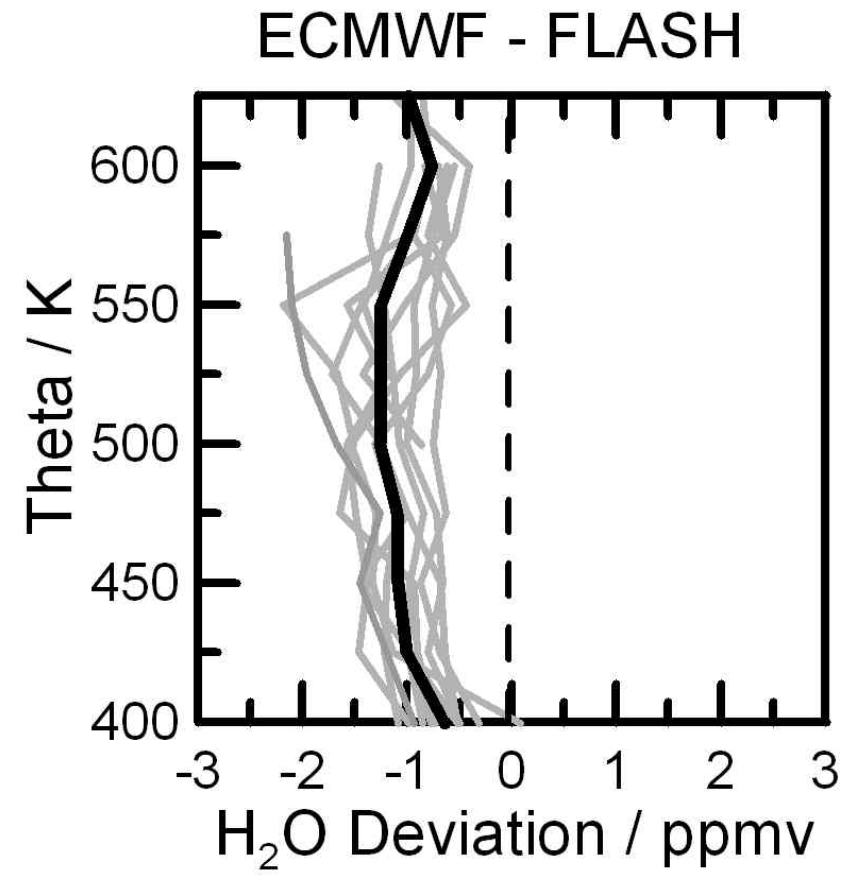

Fig. 2. Difference in water vapour mixing ratio between ECMWF T106 analyses and the 11 FLASH measurements (grey lines), the mean deviation profile (black line) revealing that the ECMWF analyses are about 1 ppmv drier than the observations.

the MIMOSA model is operated advecting potential vorticity (PV) in order to reproduce the large and fine scale structures of the polar vortex. It should be mentioned that advected potential vorticity is a derived quantity that is conserved on isentropic surfaces and correlates with the ozone or water vapour concentration in the lower stratosphere. Advected potential vorticity values are probably higher than PV within filaments since the latter is poorly conserved due to radiative and dynamical processes. In order to correct for diabatic changes, the advected PV field is continuously relaxed toward the ECMWF PV (that takes into account for radiative processes and vertical descent) with a time constant of around 10 days. In fact, potential vorticity is assumed to be conserved on isentropic surfaces in the lower stratosphere in a period of 1-2 weeks (Hauchecorne et al., 2002). A first comparison between MIMOSA advected potential vorticity and water vapour in the lower polar stratosphere has been found a good proxy to qualitatively explain water vapour layering (Müller et al., 2003).

As the polar vortex deformed and shifted largely during the LAUTLOS campaign, the balloon-borne instruments launched in Sodankylä detected different parts of the polar vortex' interior and exterior as shown in Fig. 1. In the upper panel, the MIMOSA results of PV advection on isentropic levels are presented as contour cross-section in function of time and altitude, applying modified PV according to Lait (1994) normalized at $475 \mathrm{~K}$ in order to remove the conven- tional PV's exponential growth with height for an isothermal atmosphere. While the first stratospheric payloads were launched inside of the vortex, the station was clearly out of the vortex after 8 February 2004. In the last third of the campaign, the soundings were performed in the vicinity of the vortex edge, as confirmed by the vortex edge criteria defined by Nash et al. (1996). In the centre panel of Fig. 1, a similar cross-section shows the equivalent latitude estimated from the PV field according to Nash et al. (1996). The equivalent latitude represents the latitude that an air mass would have if the polar vortex was centred at the pole, as the Ertel PV isolines are transformed on an equivalent area map projection, symmetrically arranged around the pole. The advected equivalent latitude thus allows a better characterization of the air mass origin in terms of original location relative to the polar vortex rather than in terms of geographical latitude. Underneath the cross-sections, examples of water vapour profiles measured by FLASH are given together with the water vapour profiles from the closest grid point in operational ECMWF analyses (Fig. 1, lower panel).

On 6 February 2004, the secondary vortex centre was covering northeastern Scandinavia, and the balloon entered the vortex at about $400 \mathrm{~K}$. The smooth increase of water vapour with altitude observed by FLASH represents the typical vertical distribution inside the polar vortex, where large scale descent replenishes water vapour from the high stratosphere. While below the polar vortex, in the lowermost stratosphere, a water vapour mixing ratio of about $4 \mathrm{ppmv}$ is found, values above $550 \mathrm{~K}$ exceed $6 \mathrm{ppmv}$. The high equivalent latitude confirms that the hygrometer sampled air from inside the vortex.

The polar vortex had then moved further eastward, leaving Scandinavia under the influence of mid-latitude and tropical air in the stratosphere on 11 February 2004. FLASH has detected air from clearly outside of the polar vortex. Water vapour mixing ratios are about 4 to $5 \mathrm{ppmv}$ throughout the profile, as typical for mid-latitude air (Ovarlez and Ovarlez, 1994; Schiller et al., 1996). Equivalent latitude values ranges from $45^{\circ}$ in the lower part of the profile to $25^{\circ}$ in the upper part.

On 17 February 2004, the vortex was located northeast of Scandinavia with large filaments wrapped around the edge caused by the stirring dynamics of the preceding days. The balloon trajectory transits mid-latitude air, polar air and air from lower latitudes. The measured water vapour peaks at altitudes of $525 \mathrm{~K}$ and $450 \mathrm{~K}$ potential temperature, indicating the encounter of polar vortex filaments. While the midlatitude air holds less than 5 ppmv $\mathrm{H}_{2} \mathrm{O}$, the vortex filament at $525 \mathrm{~K}$ holds about $6 \mathrm{ppmv} \mathrm{H}_{2} \mathrm{O}$. The equivalent latitude field shows the presence of layers originating in mid-latitude regions (lower part of the profile) and at the vortex edge $(525 \mathrm{~K})$. In the upper part of the profile $(575 \mathrm{~K})$, air from lower equivalent latitudes $\left(30^{\circ}\right)$ pronounces the strong vertical water vapour gradient observed around the polar air peak at $525 \mathrm{~K}$. 

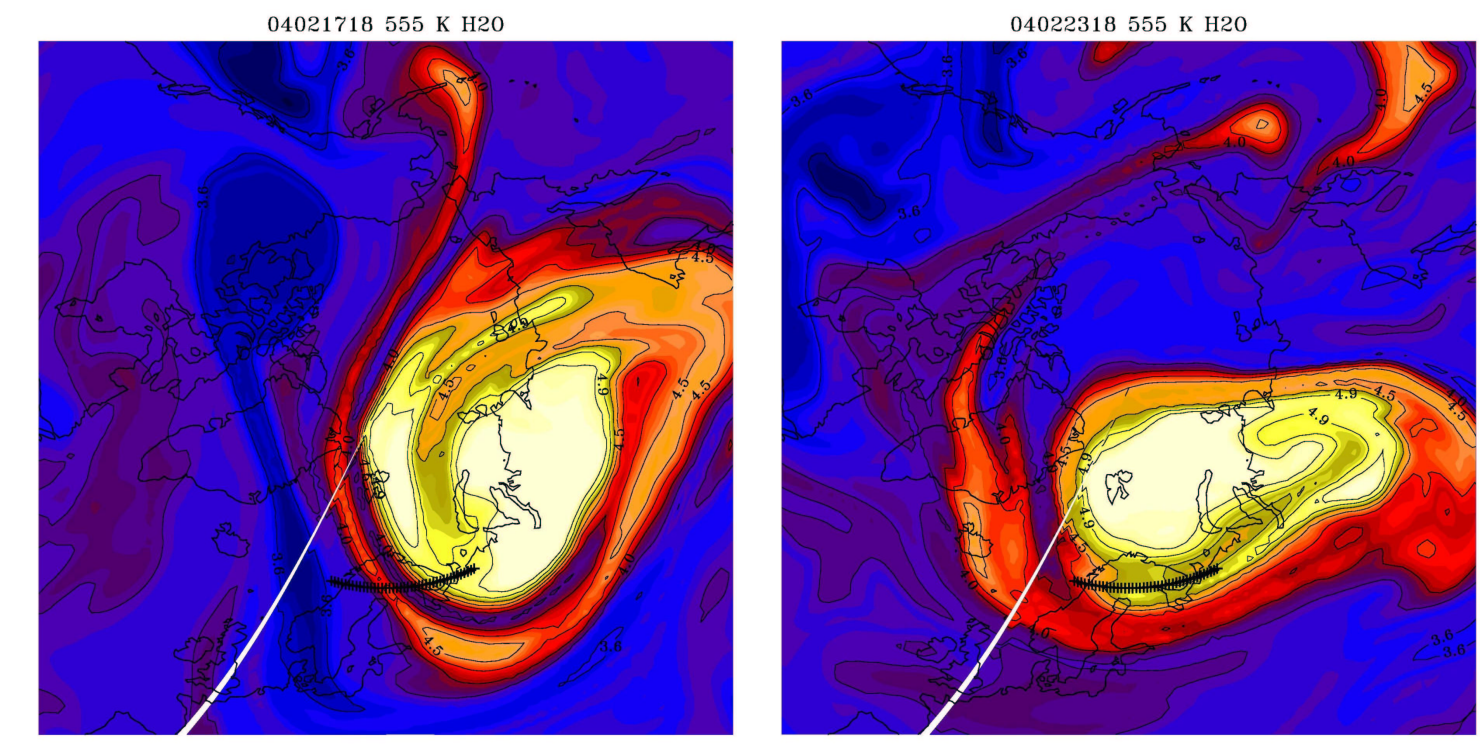

3.5

4.0

4.5

ppmv

Fig. 3. Water vapour from ECMWF advected with MIMOSA on the $555 \mathrm{~K}$ level on 17 February 2004 (left) and on 23 February 2004 (right). The black line shows the location of the cross-section shown in Figs. 7 and 8.

By 23 February the polar vortex had shifted towards Scandinavia, however the modified PV shows that it was rather the inner vortex edge region that covered the stratosphere above Sodankylä. The complex structure of the measured water vapour profile again indicates the influence of different air-masses. Below $450 \mathrm{~K}$, the constant values of about $4.5 \mathrm{ppmv}$ are obviously related to air originating from the mid-latitudes, as confirmed by the equivalent latitude. Above that level, the profile is composed by interleaving layers originating from middle to high equivalent latitudes, giving a very irregular vertical gradient to the measured water vapour.

Overall, the high-resolution PV fields and equivalent latitude simulated with MIMOSA allow to interpret the differences in the measured water vapour profiles to be caused by the different origin of air, with vortex air containing about 12 ppmv more water vapour than the surrounding midlatitude air. The good correlation of MIMOSA PV structures and the observed water vapour profiles implies that the lower stratospheric water vapour distribution in the absence of condensation is controlled by dynamics which are well represented by the horizontal wind field provided by ECMWF.

\section{Comparison with stratospheric humidity analyses}

The observed vertical water vapour distribution has qualitatively been proven to be affected by large scale vortex descent and mesoscale processes at the vortex edge. Regarding the water vapour quantity, the measured profiles are now compared to the stratospheric water vapour distribution as given by the operational ECMWF stratospheric humidity analyses. The ECMWF parameter specific humidity has been converted to water vapour volume mixing ratio by multiplying with $1.6 \times 10^{6}$ in order to allow the direct comparison with the humidity quantity measured by the FLASH instrument. In the vertical, the ECMWF analysis data have been interpolated to potential temperature levels with steps of $25 \mathrm{~K}$. A first confrontation of ECMWF analyses and FLASH measurements is given by the water vapour profiles in Fig. 1 (lower panel).

To systematically analyse the deviation of all profiles, the high-resolution FLASH profiles have been adapted to the $25 \mathrm{~K}$ height steps by averaging the water vapour mixing ratio in the according theta level $+/ 5 \mathrm{~K}$. The deviation of the operational ECMWF humidity analyses from the measured profiles up to $625 \mathrm{~K}$ is shown in Fig. 2. Obviously, in the lower stratosphere above $400 \mathrm{~K}$ the analysis data are generally much dryer than the observations. No dependence on the location relative to the vortex was substantiated, e.g. if the profile was detected inside, outside or at the edge of the polar vortex. Yet, looking separately at each of these three subgroups assorted according to the relative vortex location, it was found that the deviation slightly increased with time during the campaign period, indicating a possible problem with the vertical replenishment in the model. On average, 


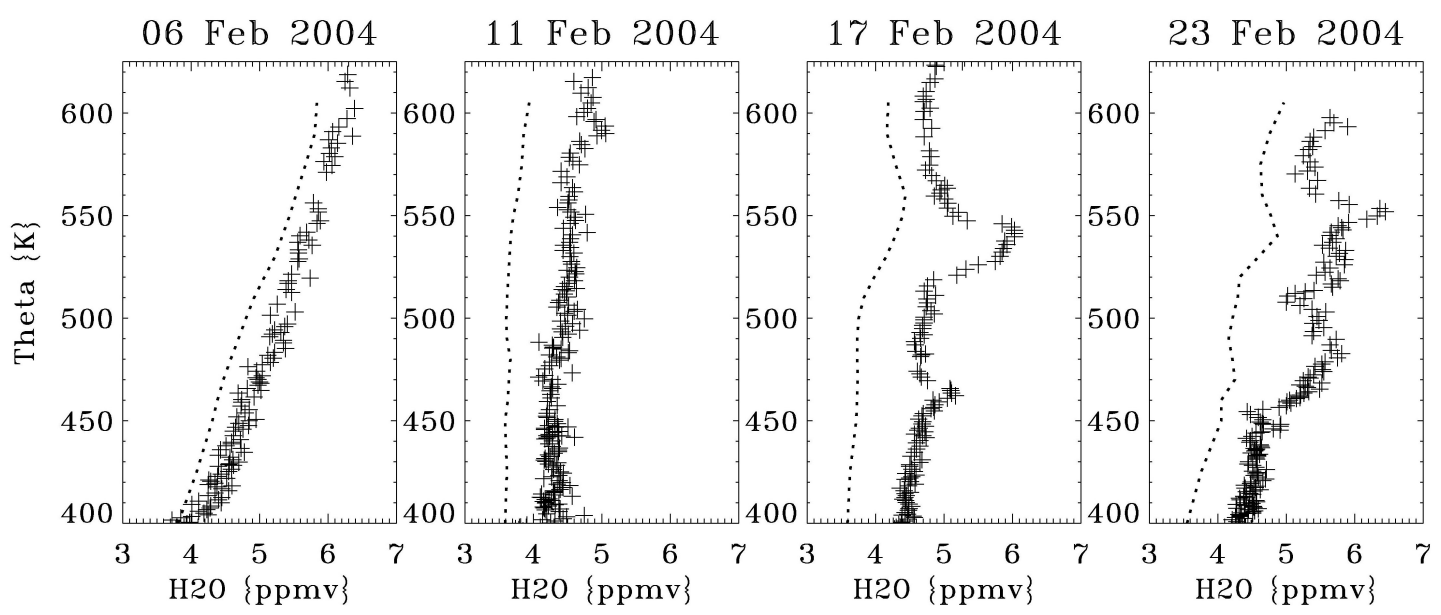

Fig. 4. Profiles of water vapour on $06,11,17$, and 23 February 2004 as measured by FLASH (black crosses), as well as from ECMWF analyses advected with MIMOSA (black lines).

a dry bias of about 1 ppmv is found throughout the lower stratosphere, accounting for a relative difference from the measurements in the order of $20 \%$.

Improvement of the $\mathrm{H}_{2} \mathrm{O}$ model representation in the lower stratosphere is expected to be achieved by reconstructing the analysis humidity distribution with the MIMOSA advection scheme. In a first approach, the MIMOSA transport is directly applied to the operational ECMWF analysis humidity as initial tracer. The fine scale horizontal water vapour distribution from MIMOSA-ECMWF on the $555 \mathrm{~K}$ potential temperature level is shown in Fig. 3 for 17 and 23 February. The first case is characterised by the presence of an elongated filament peeled off the polar vortex. A thin tongue of mid-latitude air originating from the North Pacific region is enclosed by the filament and the vortex. By February 23 the polar vortex had moved, covering the northern part of Scandinavia while the major part of the former vortex filament is now explicitly separated from the vortex. In fact, higher water vapour mixing ratios originating from vortex filamentation are now found in the North Pacific region. Similar phenomena on larger time scales have been described by Durry and Hauchecorne (2005) for mid-latitude stratospheric $\mathrm{H}_{2} \mathrm{O}$ soundings during early summer. As for the Sodankylä $\mathrm{H}_{2} \mathrm{O}$ measurement on 23 February, the hygrometer was launched in the inner vortex edge region where both $\mathrm{H}_{2} \mathrm{O}$ rich and drier air-masses are present, originating from polar and midlatitudes, respectively.

In Fig. 4, some examples of $\mathrm{H}_{2} \mathrm{O}$ profiles resulting from the MIMOSA advection of ECMWF humidity are shown together with those measured by FLASH. For the profiles composed of layers with different origin (e.g. 17 and 23 February 2004), MIMOSA is capable to produce filamentary structures in water vapour. Generally, the largest improvements of the MIMOSA three-dimensional field reconstruction compared to the operational ECMWF analysis are found in re- gions where strong gradients in humidity occur. Obviously, the largest horizontal water vapour gradient is found at the polar vortex edge where filamentation leads to laminae structures in the vertical $\mathrm{H}_{2} \mathrm{O}$ profile. Due to the small scale structures, a high resolution of transport processes is necessary to resolve the vortex edge region and the according tracer distribution in a realistic way. The MIMOSA horizontal transport based on the ECMWF wind field is proven to match the observed trace gas structures and to qualitatively provide the $\mathrm{H}_{2} \mathrm{O}$ distribution in the Arctic stratosphere. Still, the quantitative deviation of the MIMOSA advected humidity to the measured profiles remains in the order of $1 \mathrm{ppmv}$ due to the dry bias introduced by the initial ECMWF stratospheric humidity analyses. Using ECMWF data with the higher vertical resolution of model levels instead of pressure levels may result in a better representation of small scale structures, but has no significant influence on the humidity quantity. The MIMOSA-ECMWF overall stratospheric water vapour distribution above Sodankylä is shown in the altitude-time cross-section in Figure 5, reflecting the vortex movement above the station as described by the modified PV in Fig. 1.

In a second approach to improve the $\mathrm{H}_{2} \mathrm{O}$ model representation, the correlation between water vapour and modified PV is used to reconstruct the $\mathrm{H}_{2} \mathrm{O}$ distribution with MIMOSA. Here, the quantitative correlation between measured water vapour and MIMOSA modified potential vorticity (MPV) is calculated on individual potential temperature $(\Theta)$ surfaces, for convenience grouped to 3 major potential temperature layers centred at $395 \mathrm{~K}, 490 \mathrm{~K}$, and $595 \mathrm{~K}$, respectively. These layers ( 350 to $440 \mathrm{~K}, 440$ to $540 \mathrm{~K}$, and 540 to $630 \mathrm{~K}$ ) have been chosen to cover the maximum number of available measurements as well as the maximum variability in PV. For all February measurements, the $\mathrm{H}_{2} \mathrm{O}$ data are included and combined with the MIMOSA MPV values 

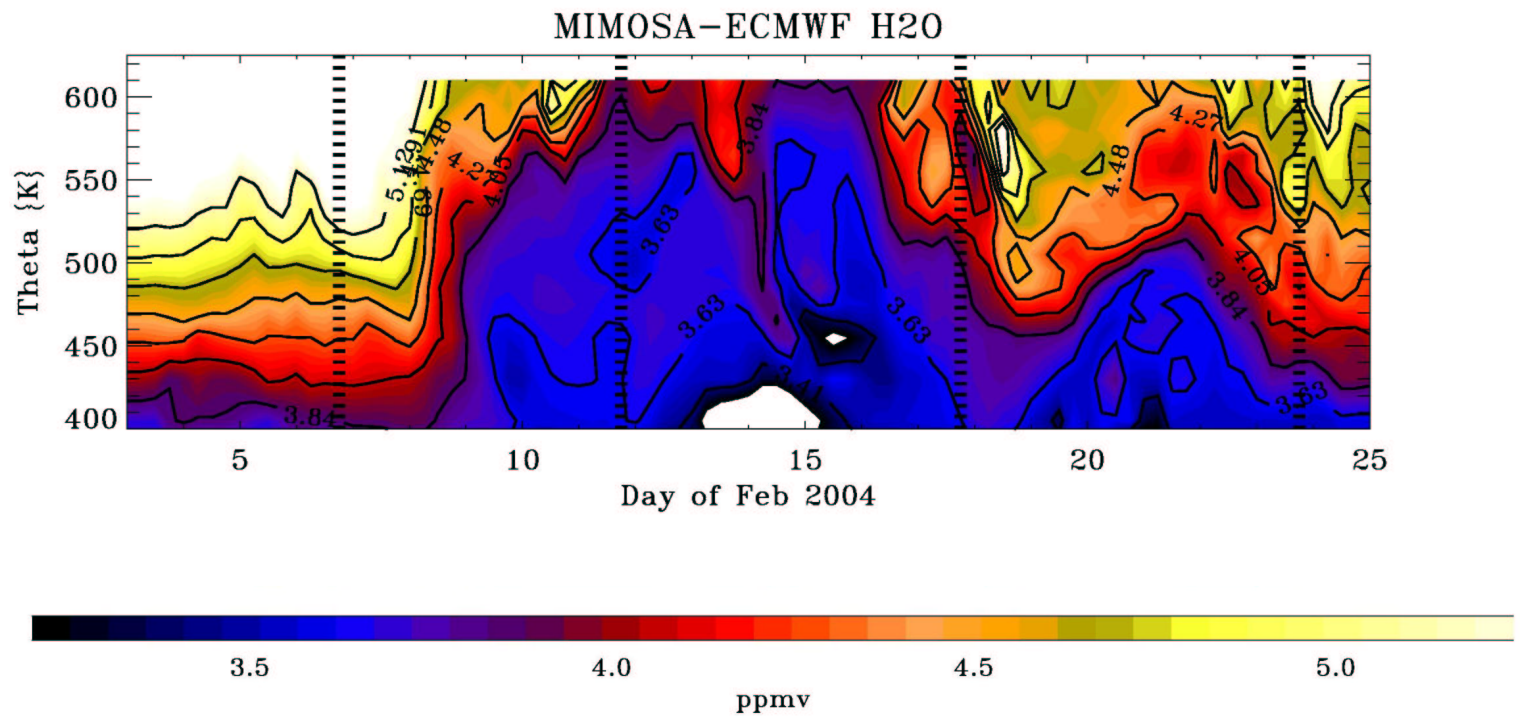

Fig. 5. Water Vapour from ECMWF analyses advected with MIMOSA, for the time period 1 to 25 February 2004 above Sodankylä. The dotted lines indicate the date of the profiles shown in Fig. 4.
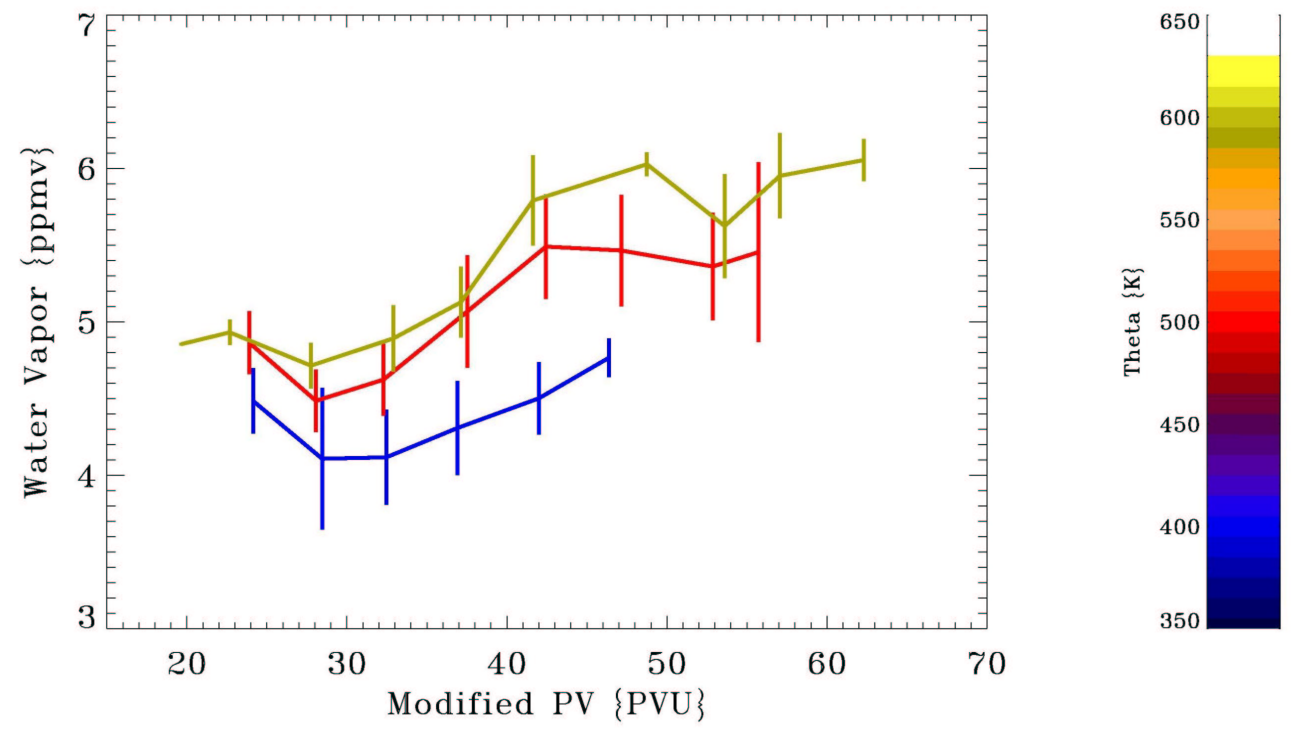

Fig. 6. Correlation of water vapour measured by FLASH and modified potential vorticity as simulated by MIMOSA PV runs, for the period February 2004 in the Arctic. The color-coded lines show the MPV- $\mathrm{H}_{2} \mathrm{O}$ correlation for the layers centred around $395 \mathrm{~K}$ (blue), $490 \mathrm{~K}$ (red), and $595 \mathrm{~K}$ (yellow), with the vertical lines indicating the standard deviation for all measurements attributing to the according potential temperature range ( 350 to $440 \mathrm{~K}, 440 \mathrm{~K}$ to $540 \mathrm{~K}$, and $540 \mathrm{~K}$ to $630 \mathrm{~K}$, respectively).

on $\Theta$-levels in steps of $10 \mathrm{~K}$, thus about $100 \mathrm{H}_{2} \mathrm{O}-\mathrm{MPV}$ data pairs contribute to the correlation of each potential temperature layer shown in Fig. 6. Clearly, the validity of such an empirical correlation between water vapour and modified potential vorticity is restricted to the time and region of enhanced stratospheric water vapour measurement activity, respectively, as well as to conditions where stratospheric water vapour can be considered a passive tracer. The initial water vapour field for the MIMOSA advection is then generated via the PV field by applying the retrieved empirical correlation. The approach is justified by the fact that the comparison between MPV and water vapour has been shown to be robust. Nevertheless, this second method can be considered valid only for the PV range where sufficient water vapour data points are available. 

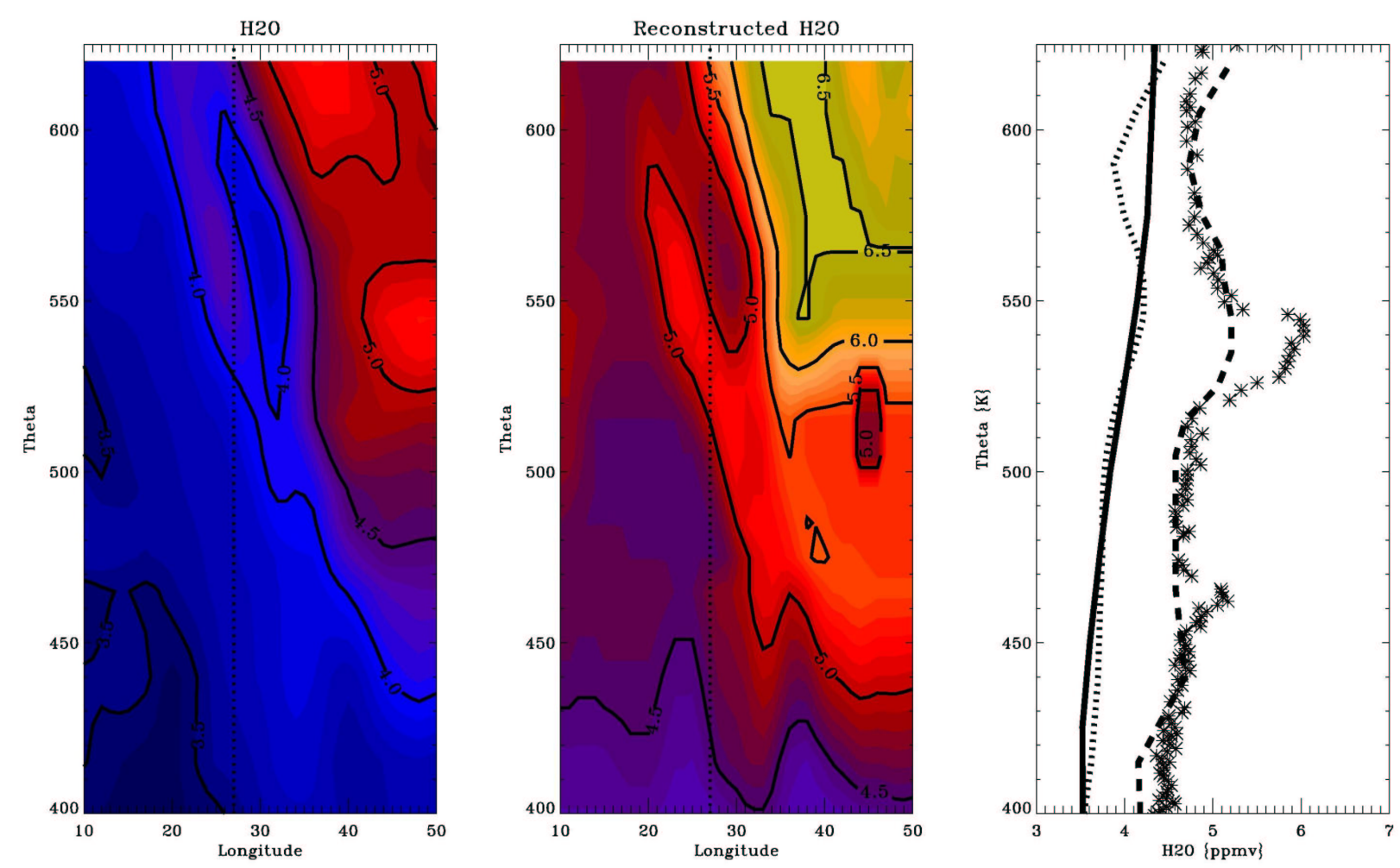

4

5

H20 \{ppmv\}

6

7

Fig. 7. Longitude-altitude cross-section for the transect on 17 February 2004 indicated in Fig. 3, showing ECMWF water vapour advected with MIMOSA (left) and reconstructed water vapour applying the empirical MPV- $\mathrm{H}_{2} \mathrm{O}$ correlation to MIMOSA PV fields (center). The right panel shows the profiles from ECMWF humidity analysis (black line), MIMOSA humidity reconstruction based on ECMWF humidity (dotted line), MIMOSA humidity reconstruction based on MPV correlation (dashed line), and as measured by FLASH (crosses).

The altitude-longitude cross sections of the water vapour distribution as reconstructed with both approaches, the MIMOSA advection applied directly to ECMWF humidity on the one hand and associated with the empirical $\mathrm{H}_{2} \mathrm{O}-\mathrm{MPV}$ correlation on the other hand, are shown in Figs. 7 and 8 together with the measured water vapour profiles above Sodankylä for 17 and 23 February, respectively.

On 17 February, the filamentary structure identified earlier in the horizontal map appears from $500 \mathrm{~K}$ to $600 \mathrm{~K}$ in the vertical and is tilted with longitude. Moreover, air with low $\mathrm{H}_{2} \mathrm{O}$ mixing ratio is confined between the filament and the vortex. The water vapour distribution achieved from the $\mathrm{H}_{2} \mathrm{O}-\mathrm{MPV}$ correlation shows a similar pattern, but the absolute values cover a wider range and the filament appears more clearly defined. In fact, the comparison of the measured and reconstructed $\mathrm{H}_{2} \mathrm{O}$ profiles (Fig. 7, right panel) shows that the PVbased reconstruction allows not only to reproduce more accurately the vertical gradient but also to minimise the over- all bias. In general, the measured $\mathrm{H}_{2} \mathrm{O}$ data show a larger variability at the edge of the polar vortex with respect to the ECMWF analyses humidity. Combined with the broad range of PV values in the vicinity of the vortex, a more detailed and more accurate description of the vertical $\mathrm{H}_{2} \mathrm{O}$ gradient is achieved when applying the $\mathrm{H}_{2} \mathrm{O}-\mathrm{MPV}$ reconstruction.

Similar analysis can be carried out for 23 February, when measurements were taken in the proximity of the vortex edge. The constant low water vapour values measured below $450 \mathrm{~K}$ suggest that the hygrometer was outside the polar vortex in this lower part of the profile. Above, it is possible to identify a main layer of vortex air, interleaved with remnants of mid-latitude air between 500 and $525 \mathrm{~K}$, and by inner-vortex air at $550 \mathrm{~K}$. Both ECMWF humidity and MPV$\mathrm{H}_{2} \mathrm{O}$ MIMOSA reconstructions qualitatively show the presence of such structure, but only the PV-based reconstruction improves also quantitatively by better representing the vertical gradient and significantly reducing the bias. 

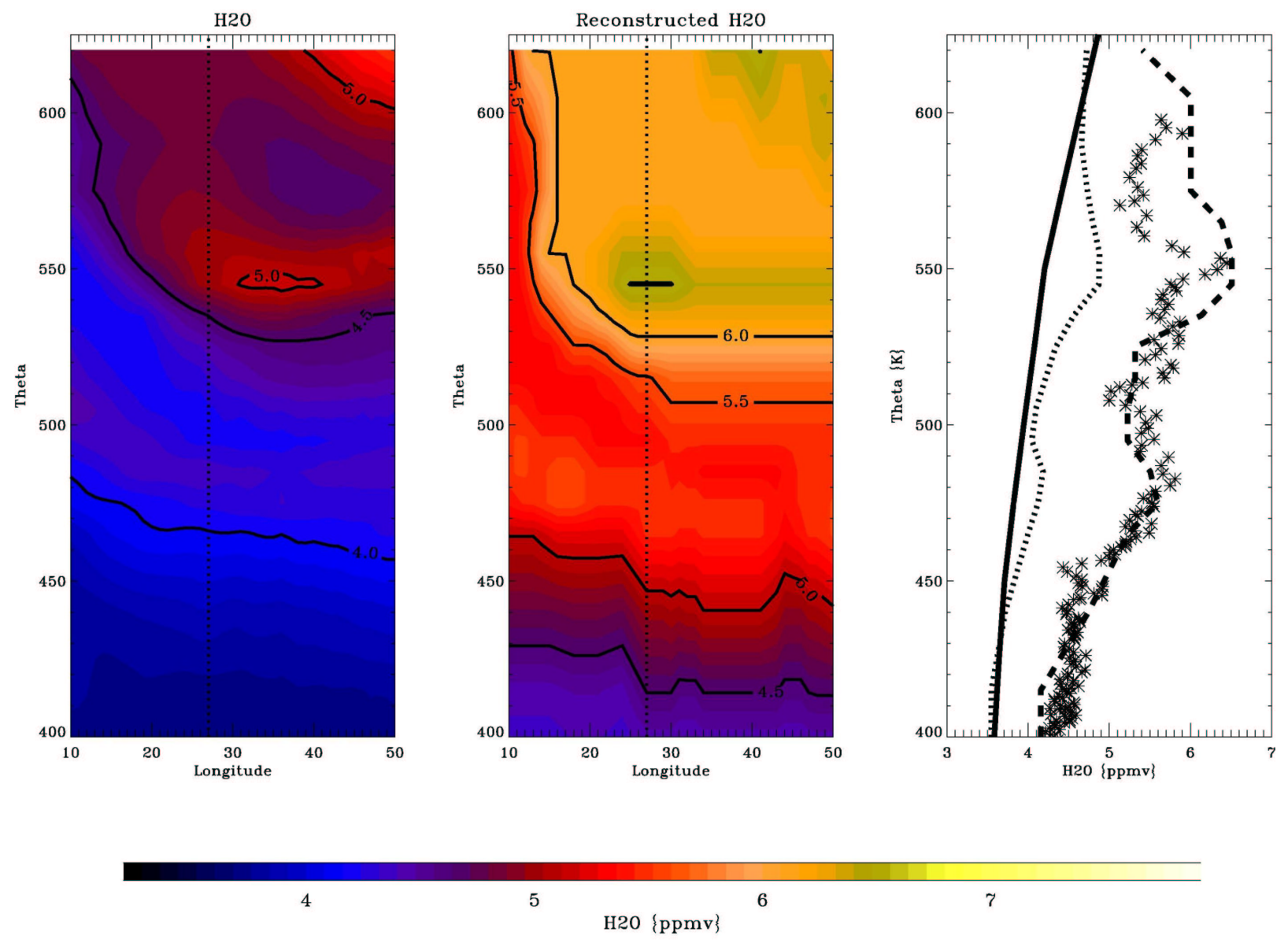

Fig. 8. Longitude-altitude cross-section for the transect on 23 February 2004 indicated in Fig. 3, showing ECMWF water vapour advected with MIMOSA (left) and reconstructed water vapour applying the empirical MPV- $\mathrm{H}_{2} \mathrm{O}$ correlation to MIMOSA PV fields (center). The right panel shows the profiles from ECMWF humidity analysis (black line), MIMOSA humidity reconstruction based on ECMWF humidity (dotted line), MIMOSA humidity reconstruction based on MPV correlation (dashed line), and as measured by FLASH (crosses).

\section{Discussion}

It has been shown that MIMOSA is able to reproduce weak water vapour filaments from ECMWF analysis humidity, but obviously the large bias induced by the initial $\mathrm{H}_{2} \mathrm{O}$ field exceeds by far any improvement introduced by the better representation of the dynamical field. When comparing the water vapour data given by the initial ECMWF humidity field and the balloon-borne FLASH measurements, large discrepancies are found because the model strongly underestimates the lower stratospheric humidity. While we focus on the Arctic lower stratosphere, similar deviations of the model have been noted earlier for aircraft measurements in the extratropical UTLS region (Ovarlez et al., 2000) and for UARS data in the tropical middle stratosphere (ECMWF Newsletter No.82 www.ecmwf.int/publications/newsletters/). It is known that ECMWF stratospheric analyses had been too dry when methane oxidation in the upper stratosphere was not yet implemented (Simmons et al., 1999). This high level $\mathrm{H}_{2} \mathrm{O}$ source has now been amended, and the representation of the ECMWF stratospheric humidity distribution has been further improved with the higher vertical resolution of the model, as transport processes are reproduced on more realistic timescales in the 50-level simulations (Simmons et al., 1999). Yet in the ECMWF analysis system, stratospheric humidity evolves solely according to the dynamical and parameterized physical processes within the model and thus depends completely on the tropical tropopause temperature as stratospheric entry parameter, as well as on the strength of the meridional circulation.

The underestimation of stratospheric humidity may lead to large errors e.g. in the calculation of radiative heating rates, or in the determination of the potential polar stratospheric cloud volume that critically depends not only on temperature but also on the water vapour mixing ratio (Hanson and Mauersberger, 1988; Marti and Mauersberger, 1993). Our 
study underlines the need for further reliable measurements of stratospheric water vapour for the validation of climate models.

\section{Summary}

During the LAUTLOS campaign in January and February 2004, water vapour profiles have been measured from Sodankylä, Finland, by different balloon-borne sensors. The retrieved dataset of high-resolution stratospheric water vapour profiles observed by the Russian FLASH-B instrument provides an excellent source for model validation in the Arctic region, as the measurements cover a period of about one month. As the polar vortex deformed and shifted during the campaign period, the water vapour mixing ratio was detected inside and in the vicinity of the polar vortex. To analyse the effects of the winter stratosphere dynamics on the water vapour distribution, we combined the $\mathrm{H}_{2} \mathrm{O}$ profiles measured by FLASH with the semi-lagrangian advection model MIMOSA. By correlating water vapour and potential vorticity as described in Müller et al. (2003), it was possible to identify water vapour profiles typical for the polar vortex interior and exterior. Furthermore, laminae in the water vapour profiles have been assigned to dynamically caused filamentary structures at the vortex edge. The structures in the high-resolution PV fields simulated with MIMOSA correlate well with the observed water vapour mixing ratio, implying that in the absence of condensation the lower Arctic stratospheric water vapour distribution is purely controlled by dynamics that are well represented by the initial horizontal wind field provided by ECMWF.

To proceed to a quantitative comparison of measured and simulated stratospheric water vapour, specific humidity from operational ECMWF analyses has been 3-dimensionally advected as passive tracer by MIMOSA. Although filamentary structures become also apparent in the resulting $\mathrm{H}_{2} \mathrm{O}$ mixing ratio fields, large discrepancies occur when comparing the profiles with the measurements. The lower stratosphere above $400 \mathrm{~K}$ is generally too dry by about $1 \mathrm{ppmv}$ throughout the lower stratosphere both in the initial ECMWF and the MIMOSA fields. With total $\mathrm{H}_{2} \mathrm{O}$ mixing ratios of about 4 to 6 ppmv, the dry bias of the models is in the order of $20 \%$. Apart from the large quantitative deviation, MIMOSA appears to generally reproduce the shape of the profiles better than the ECMWF analysis with the largest improvement in the region of the strongest horizontal water vapour gradient (at the vortex edge). Although MIMOSA has been proven to rudimentary reproduce water vapour filaments, the large bias induced by the initial $\mathrm{H}_{2} \mathrm{O}$ field exceeds by far any improvement introduced by the better representation of the dynamical field. Similar discrepancies of the $\mathrm{H}_{2} \mathrm{O}$ field given by the operational ECMWF analyses have been found earlier for measurements in the extratropical UTLS region (Ovarlez et al., 2000) and in the tropical middle stratosphere. The de- viation of the model from the observations emphasizes the problem in using ECMWF analysed stratospheric humidity for e.g. the calculation of radiative heating rates.

To achieve an improvement of the simulated stratospheric water vapour in the vicinity of the polar vortex, we calculated the quantitative correlation between water vapour measured during the LAUTLOS campaign and the modified potential vorticity. The MIMOSA transport scheme was then initialised with the given MPV-correlated water vapour distribution, reproducing water vapour mixing ratio in good agreement with the measurements. The method may improve the model description of the water vapour in the stratosphere, but is clearly restricted to periods of enhanced stratospheric $\mathrm{H}_{2} \mathrm{O}$ measurement activity.

The presented comparison has impressively proven that there is a large dry bias in the ECMWF analysis representation of stratospheric water vapour in the Arctic, and that future regular measurements of water vapour in the polar regions are essential for the validation and improvement of climate models.

Acknowledgements. This work was supported within COST723 by the European Science Foundation. We thank the colleagues who were involved in the LAUTLOS campaign: U. Leiterer, H. Vömel, R. Kivi, R. Neuber, P. Ruppert, A. Paukkunen, N. Kämpfer, nd their co-workers. We specifically wish to thank the FMI team, lead by E. Kyrö, for arranging the campaign at Sodankylä. The LAUTLOS campaign was funded by the EU project LAPBIAT. Financial support was also given by the Russian Based Research Program (RFFI grant 04-05-64723). We thank the European Centre for MediumRange Weather Forecast for supplying the meteorological data.

Topical Editor F. D' Andrea thanks two referees for their help in evaluating this paper.

\section{References}

Abbas, M. M., Michelsen, H. A., Gunson, M. R., Abrams, M. C., Newchurch, M. J., Salawitch, R. J., Chang, A. Y., Goldman, A., Irion, F. W., Manney, G. L., Moyer, E. J., Nagaraju, R., Rinsland, C. P., Stiller, G. P., and Zander, R.: Seasonal variations of water vapour in the lower stratosphere inferred from ATMOS/ATLAS3 measurements of $\mathrm{H}_{2} \mathrm{O}$ and $\mathrm{CH}_{4}$, Geophys. Res. Let., 23, 24012404, 1996.

Appenzeller, C. and Holton, J. R.: Tracer lamination in the stratosphere: A global climatology. J. Geophys. Res., 102, $13555-$ $13569,1997$.

Bertaux, J.-L. and Delannoy, A.: Vertical distribution of $\mathrm{H}_{2} \mathrm{O}$ in the stratosphere as determined by UV fluorescence in-situ measurements. Geophys. Res. Let., 5, 1017-1020, 1978.

Brasseur, G. and Solomon, S. (Eds.): Aeronomy of the Middle Atmosphere, D. Reidel Publishing Company, Dordrecht, 229-237, 1984.

Brewer, A. W.: Evidence for a world circulation provided by the measurements of helium and water vapour distribution in the stratosphere, Q. J. R. Meteorol. Soc., 75, 351-363, 1949.

Deuber, B., Haefele, A., Feist, D. G., Martin, L., Kämpfer, N., Nedoluha, G. E., Yushkov, V., Khaykin, S., Kivi, R., and 
Vömel, H.: Middle Atmospheric Water Vapour Radiometer (MIAWARA): Validation and first results of the LAPBIAT Upper Tropospheric Lower Stratospheric Water Vapour Validation Project (LAUTLOS-WAVVAP) campaign. J. Geophys. Res., 110, D13306, doi:10.1029/2004JD005543, 2005.

Durry, G. and Hauchecorne, A.: Evidence for long-lived polar vortex air in the mid-latitude summer stratosphere from in situ laser diode $\mathrm{CH}_{4}$ and $\mathrm{H}_{2} \mathrm{O}$ measurements, Atmos. Chem. Phys., 5, 1467-1472, 2005.

Evans, S. J., Toumi, R., Harries, J. E., Chipperfield, M. P., and Russell III, J. M.: Trends in stratospheric humidity and the sensitivity of ozone to these trends. J. Geophys. Res., 103, 8715-8725, 1998.

Forster, P. M. de F. and Shine, K. P.: Stratospheric water vapour changes as a possible contributor to observed stratospheric coolingn, Geophys. Res. Lett., 26, 3309-3312, 1999.

Hanson, D. R. and Mauersberger, K.: Laboratory studies of the nitric acid trihydrate: implications for the south polar stratosphere, Geophys. Res. Lett., 15, 855-858, 1988.

Hauchecorne, A., Godin, S., Marchand, M., Heese, B., and Souprayen C.: Quantification of the transport of chemical constituents from the polar vortex to midlatitudes in the lower stratosphere using the high-resolution advection model MIMOSA and effective diffusivity. J. Geophys. Res., 107 (D20), 8289, doi:10.1029/2001JD000491, 2002.

Heese, B., Godin, S., and Hauchecorne, A.: Forecast and simulation of stratospheric ozone filaments: A validation of a highresolution potential vorticity advection model by airborne ozone lidar measurements in winter 1998-1999, J. Geophys. Res., 106, 20011-20024, 2001.

Kirk-Davidoff, D. B., Hintsa, E. J., Anderson, J. G., and Keith, D. W.: The effect of climate change on ozone depletion through changes in stratospheric water vapour, Nature, 402, 399-401, 1999.

Kley, D. and Stone, E. J.: Measurement of water vapour in the stratosphere by photodissociation with Ly- $\alpha(1216 \AA)$ light, Rev. Sci. Instrum., 49, 691-697, 1978.

Lait, L.R.: An alternative form for potential vorticity, J. Atmos. Sci., 51, 1754-1759, 1994.

Marti, J. and Mauersberger, K.: A survey and new measurements of ice vapour pressure at temperature between 170 ad $250 \mathrm{~K}$, Geophys. Res. Lett., 20, 363-366, 1993.

McKenna, D. S., Konopka, P., Grooß, J.-U., Günther, G., Müller, R., Spang, R., Offermann, D., and Orsolini, Y.: A new Chemical Lagrangian Model of the Stratosphere (CLaMS) 1. Formulation of advection and mixing, J. Geophys. Res., 107 (D16), 4309, doi:10.1029/2000JD000114, 2002.

Michelsen, H. A., Irion, F. W., Manney, G. L., Toon, G. C., and Gunson, M. R.: Features and trends in Atmospheric Trace Molecule Spectroscopy (ATMOS) version 3 stratospheric water vapour and methane measurements, J. Geophys. Res., 105, 22 713-22 724, 2000.

Müller, M., Neuber, R., Fierli, F., Hauchecorne, A., Vömel, H., and Oltmans, S. J.: Stratospheric water vapour as tracer for vortex filamentation in the Arctic winter 2002/2003, Atmos. Chem. Phys., 3, 1991-1997, 2003.
Nash, E. R., Newman, P. A., Rosenfield, J. E., and Schoeberl, M. R.: An objective determination of the polar vortex using Ertel's potential vorticity, J. Geophys. Res., 101, 9471-9478, 1996.

Newman, P. A., Lait, L. R., Schoeberl, M. R., et al.: Measurements of polar vortex air in the midlatitudes, J. Geophys. Res., 101, 12 879-12 891, 1996.

Oinas, V., Lacis, A. A., Rind, D., Shindell, D. T., and Hansen J. E.: Radiative cooling by stratospheric water vapour: big differences in GCM results, Geophys. Res. Lett., 28, 2791-2794, 2001.

Oltmans, S. J. and Hofmann, D. J.: Increase in lower-stratospheric water vapour at a mid-latitude Northern Hemisphere site from 1981-1994, Nature, 374, 146-149, 1995.

Oltmans, S. J., Vömel, H., Hofmann, D. J., Rosenlof, K. H., and Kley, D.: The increase in stratospheric water vapour from balloonborne frostpoint hygrometer measurements at Washington, D.C. and Boulder, Colorado, Geophys. Res. Lett., 27, 34533456, 2000.

Ovarlez, J. and Ovarlez, H.: Stratospheric water vapour content evolution during EASOE. Geophys. Res. Lett., 21, 1235-1238, 1994.

Ovarlez, J., van Velthoven, P., Sachse, G., Vay, S., Schlager, H., and Ovarlez, H.: Comparison of water vapour measurements from POLINAT 2 with ECMWF analyses in high-humidity conditions, J. Geophys. Res., 105, 3737-3744, 2000.

Rosenlof, K. H., Oltmans, S. J., Kley, D., et al.: Stratospheric water vapour increases over the past half century, Geophys. Res. Let., 28, 1195-1198, 2001.

Schiller, C., Engel, A., Schmidt, U., Borchers, R., and Ovarlez, J.: The partitioning of hydrogen species in the Arctic winter stratosphere: Implications for microphysical parameters, J. Geophys. Res., 101, 14 489-14 493, 1996.

Simmons, A. J., Untch, A., Jakob, C., Kållberg, P., and Undén, P.: Stratospheric water vapour and tropical tropopause temperatures in ECMWF analyses and multi-year simulations, Q. J. R. Meteorol. Soc., 125, 353-386, 1999.

Smith, C. A., Haigh, J. D., and Toumi, R.: Radiative forcing due to trends in the stratospheric water vapour, Geophys. Res. Lett., 28, 179-182, 2001.

Vömel, H., Oltmans, S. J., Hofmann, D. J., Deshler, T., and Rosen, J. M.: The evolution of the dehydration in the Antarctic stratospheric vortex, J. Geophys. Res., 100, 13 919-13 926, 1995.

Waugh, D. W., Plumb, R. A., Atkinson, R. J., et al.: Transport out of the polar vortex by Rossby wave breaking, J. Geophys. Res., 99, 1071-1088, 1994.

Yushkov V., Merkulov, S., and Astakhov, V.: Optical balloon hygrometer for upper stratosphere and stratosphere water vapour measurements, in: Optical Remote Sensing of the Atmosphere and Clouds, Proceedings of SPIE, Vol. 3501, edited by: Wang, J., Wu, B., Ogawa, T., and Guans, Z.-H., 439-445, 1998.

Yushkov, V., Sitnikov, N., Zaitsev, I., Pommereau, J.-P., and Garnier, A.: Stratospheric water vapour measurements in the winter arctic with optical fluorescent hygrometer on short and long duration balloons, Proceedings of the 15th ESA symposium on European Rocket and Balloon Programmes and Related Research, edited by: Warmbein, B., ESA-SP-471, 263-268, 2001. 